\title{
Aspectos fenológicos, ecológicos e de produtividade da Graviola (Annona muricata L.) na regiào de Manaus
}

\author{
Martha de Aguiar Falcão (') \\ Eduardo Lleras ${ }^{(2}$ ) \\ Ângela Maria Conte Leite $\left(^{2}\right)$
}

\begin{abstract}
Resumo
São apresentados dados de fenologia, ecologia e produtividade da Graviola (Annona muricata L.) para a região de Manaus. A floração e frutificação são contínuas durante o ano, com ligeiro pico de floraçăo entre setembro e janeiro, e aumento ligeiro de frutos maduros entre julho e setembro. Ainda se existe correlação entre floração e frutos imaturos $(r=0,59)$ o mesmo não se observa com relação a frutos maduros (safra), o que sugere que a produtividade não está sendo limitada por controle endógeno. Com uma produtividade média aproximada de $16 \mathrm{~kg}$ por árvore, os resultados não diferem consideravelmente dos observados em outras regiōes: porém, o tamanho médio dos frutos parece ser menor. São feitas uma série de sugestões de pesquisa para tentar aumentar a produtividade. Foram encontradas 4 espécies de besouros pertencentes à familia Chrysomelidae (Alticinae) visitando as flores.
\end{abstract}

\section{INTRODUÇÃo}

Embora a região amazônica apresente uma grande diversidade de espécies frutíferas nativas, existem numerosos problemas quanto à cultura destas, face, em grande parte, à falta de conhecimentos básicos quanto à biologia e ecologia das mesmas.

Em seguimento às pesquisas sobre "aspectos fenológicos, ecológicos e de produtividade sobre algumas fruteiras da Amazônia" que já inclui pesquisas sobre o umari, mapati, pajurá, sorva e biribá, apresentam-se aqui algumas considerações sobre a graviola, Anonona muricata $\mathrm{L}$.

\section{MATERIAIS E MÉtodos}

Para este estudo, foram esco'hidas 10 árvores de graviola, estando 7 indivíduos localizados no sítio NAF 6, Km 14 da estrada Ma-

(1) - Fundação Universidade do Amazonas, Manaus.

(2) - Instituto Nacional de Pesquisas da Amazônia, Manaus.
naus-Caracaraí e 3 no campus do Instituto Nacional de Pesquisas da Amazônia (INPA). Amostras testemunhas foram depositadas no herbário do INPA.

As observações fenológicas e ecológicas foram realizadas semanalmente durante o período de floração e frutificação. Para estimar o número de flores, foram escolhidos três galhos ao acaso em cada árvore, sendo contado o número de flores dos mesmos, fazendo-se também a contagem total de galhos para estimar-se o número total de flores por árvore.

Em um intuito de determinar-se a existência ou não de autopolinização, dez flores de cada árvore foram cobertas com sacos de murim. O pólen encontrado nos insetos que freqüentam a gravioleira, foi identificado por comparação com o pólen retirado diretamente de flores da espécie e os grãos foram contados. O tratamento utilizado na preparação do pólen é o descrito por Erdtman (1960). Os insetos visitantes coletados foram identificados pelo Dr. Norman Penny da Divisão de Entomologia do INPA.

Durante a frutificação, a contagem dos frutos foi realizada nos mesmos galhos em que foram contadas as flores. Foram contados frutos imaturos e maduros e frutos caídos para poder-se determinar a percentagem de perda e o tamanho da safra. Foram pesados todos os frutos maduros de cada árvore, e logo as sementes, polpas e cascas, utilizando-se balança de precisão.

Os resultados foram submetidos a diversas análises estatísticas tais como: desvio padrão, curtose, teste d'Agostini, variância, coeficiente de variação, teste $T$, regressão linear e $X^{2}$. 
A descrição botânica foi baseada em Prance \& Silva (1975) e Cavalcante (1976), além de observações pessoais.

\section{Considerações Gerais}

Segundo Patiño (1963), a primeira referência à graviola foi feita por Oviedo em 1526, quem a citou como originária das Antilhas e dando-Ihe o nome indígena de Guanabana. Trabalhos mais recentes tais comc os de Le Cointe (1947), Fonseca (1954), Correa (1926), Patiño (1963), Prance \& Silva (1975) e Cavalcante (1976) consideraram aspectos botânicos, distribuição geográfica, usos e cultura; van der Pijl (1953) estudou a biologia floral; Moura et al. (1951) e Leung \& Flores (1961) estudaram a composição química e Clement et al. (1977) fizeram uma revisão bibliográfica sobre a mesma. É citada pela National A.cademy of Sciences (1975) como uma espécie de grande potencial, já que há uma grande demanda em todo o mundo pela mesma.

\section{ASPECTOS BOTÂNICOS}

No científico: Annona muricata L.

Nomes vulgares: Brasil: guanabano, coração de rainha; Amazonas: graviola, condessa; Pará: graviola, jaca do Pará. Suriname: zuurzak; Haiti e Antilhas Francesas: corossol; Guatemala, El Salvador, Costa Rica, Panamá, Colômbia, Venezuela e Equador: guanábana; Curaçao e Aruba: Zuurzak, sorsaka; Guiana Francesa: cachiman épineux, cachiman morreux, corossol.

\section{Família: Annonaceae}

Arvore de porte pequeno; folhas simples, alternas, pecioladas; lâmina obovada, subobovada ou oblongo-elíptica, subcorriácea; margem inteira, ápice acuminado, base subcuneada, aguda ou obtusa; muito brilhante. Flores hermafroditas, grandes, solitárias, actinomorfas, diclamídeas, com cheiro forte; sépalas 3 , pequenas, largo-ovadas, verdes, pétalas 6,3 externas, amareladas, cordiformes, côncavas, com bordos unidos no botão, prefloração valvar, ásperas por fora, 3 internas arredondadas, amareladas, côncavas, com prefloração imbricada; estames numerosos, claviformes, apinados, dispostos em um eixo hemisférico; anteras lineares, paralelas, extrorsas, rimosas, com conectivo terminal protuberante; carpelos numerosos, uniloculares, agrupados em forma de cúpula acima dos estames, estreitos; ovário súpero, freqüentemente concrescido, estiletes curtos com estígmas simples; óvulo único, anátropo. Fruto sincarpo grande, ovóide ou cordado-oblongo, carnoso, pesando de 1 a 3 quilos ou mais, resultado de numerosos pistilos unidos, cada um terminando em uma ponta mole, curva; polpa suculenta, perfumada, branca, de sabor agradável; sementes numerosas, negras ou marrons, brilhantes.

\section{DISTRIBUIÇÃo GEOGRÁFICA}

Considerada como originária das Antilhas pro Oviedo (1526, citado por Patiño, 1963), ocorre em toda América Tropical, tendo sido amplamente difundida nos trópicos de Ásia e Africa (NAS, 1975).

Usos

O fruto é comestivel, sendo utilizado para sucos, sorvetes, compotas, geléias e cremes. Atualmente, possui grande valor comercial, sendo industrializado em vários países. Quando imaturo, pode ser consumido cozido, assado ou frito (NAS, 1975).

Segundo Le Cointe (1947), é largamente utilizado na preparação de remédios caseiros, tais como tratamento de aftas em crianças, como anti-disentérico, anti-escorbútico e diurético. As flores e frutos são utilizados para tratamento de bronquites, como anti-espasmódicos, anti-reumáticos e anti-neuvrálgicos. As sementes são adstringentes e eméticas.

A madeira de cor branca ou castanha, é mole, leve e pouco durável. Em testes realizados no Museu Nacional do Rio de Janeiro, determinou-se que apresenta teores de celulose de até $64 \%$ e que é adequada para fabricação de papel. 
CARACTERÍSTICAS QUÍMICAS

Na Tabela I são apresentados os dados químicos conhecidos até o presente sobre a graviola.

TABELA 1 - Composição química da polpa da Graviola (Annona muricata L.). A, segundo Leung \& Flores (1961); B, segundo Moura et al. (1951); C, segundo Fonseca (1954)

\begin{tabular}{lccc}
\hline \multicolumn{4}{c}{ A } \\
& $\begin{array}{c}\text { B } \\
(100 \mathrm{gr})\end{array}$ & C \\
& & & \\
\hline & $100 \mathrm{gr})$ & \\
água & $83,1 \%$ & $80,5 \%$ & $81,0 \%$ \\
gordura & $0,4 \mathrm{gr}$ & $0,2 \mathrm{gr}$ & $0,8 \%$ \\
proteinas & $1,0 \mathrm{gr}$ & $1,3 \mathrm{gr}$ & $1,7 \%$ \\
carbohidratos & $14,9 \mathrm{gr}$ & $14,9 \mathrm{gr}$ & $12,0 \%$ \\
fósforo & $28,0 \mathrm{mg}$ & - & - \\
cálcio & $24,0 \mathrm{mg}$ & - & - \\
ferro & $0,5 \mathrm{mg}$ & - & - \\
vit. A & $5,0 \mathrm{mg}$ & - & - \\
riboflavina & $0,05 \mathrm{mg}$ & - & - \\
vit. C & $26,0 \mathrm{mg}$ & - & - \\
tiamina & $0,07 \mathrm{mg}$ & - & - \\
niacina & $0,9 \mathrm{mg}$ & - & - \\
sais (cinzas $)$ & $0,6 \mathrm{gr}$ & $0,6 \mathrm{gr}$ & $0,7 \%$ \\
fibras & $1,1 \mathrm{gr}$ & - & - \\
celulose & - & $2,4 \mathrm{gr}$ & $1,8 \%$ \\
\hline
\end{tabular}

Como pode ser observado, os frutos são muito ricos em carbohidratos, com baixíssimos teores de gorduras. Com pouco mais de $6 \%$ do peso seco representado por proteínas, não pode ser considerado como um fruto de grande valor protéico.

\section{Fenologia}

FLORAÇÃo

Durante a pesquisa no campo, observouse que a espécie floresce durante o ano inteiro, porém com pico de floração entre setembro e janeiro (Fig. 1). O número de flores, em comparação com outras espécies já estudadas, é reduzido, encontrando-se uma média de 84 flores produzidas por árvore durante 0 ano. As flores, solitárias, abrem gradativamente durante o dia. Após a fecundação, há abcisão das pétalas, com posterior queda dos estames até ficar o pedúnculo descoberto.
Como pode observar.se na figura 1, não existe um padrão de floração para a espécie, pelo menos na região de Manaus. parecendo ser este om fenômeno individual.

\section{FRUTIFICAÇÃo}

Como é de se esperar, a produção de frutos imaturos acompanha a floração (Fig. 1). Cavalcante (1976) anota que os frutos estão presentes nas feiras durante o ano inteiro, porém, no caso de Belém, são mais freqüentes entre o final de junho a meados de setembro. Em Manaus, encontrou-se que o período de maior frutificação corresponde aos meses de janeiro, fevereiro e março. Esta diferença em época de maior produção de frutos maduros provavelmente está ligada a fatores climáticos locais, especialmente o regime hídrico.

Segundo Cavalcante (1976) o peso dos frutos varia entre 750 a $2700 \mathrm{~g}$, anotando porém, que no Acre existem gravioleiras que produzem frutos de até $8 \mathrm{~kg}$. NAS (1975) anota o peso médio dos frutos como de aproximadamente $4 \mathrm{~kg}$. O peso médio dos frutos obtido neste trabalho, com $967 \mathrm{~g}$, coincide bem com os dados de Cavalcante (1976), o que nos leva a pensar que provavelmente o material genético proveniente da Amazônia tende a apresentar tamanho menores.

\section{MUDANÇA FOLIAR}

A mudança das folhas ocorre durante todo o ano, sendo, porém mais intensa durante o pico da safra entre janeiro e março.

\section{INSETOS VISITANTES}

Os principais visitantes da graviola foram besouros da familia Chrysomelidae (Alticinae). Estes, mais freqüentes durante a noite, se concentram no interior das flores alimentando-se das pétalas. A quantidade de pólen coletado nos mesmos foi relativamente baixa se comparada a outras espécies estudadas nesta série, com uma média de 200 grãos por lâmina, visto que a evidência atual impiica os coleópteros na polinização de Annonaceae 
(Gottsberger, 1970) devemos supor que estes sejam os polinizadores da Graviola.

Além de besouros, foram observados formigas de diversas espécies tanto na parte vegetativa quanto no exterior de botões florais

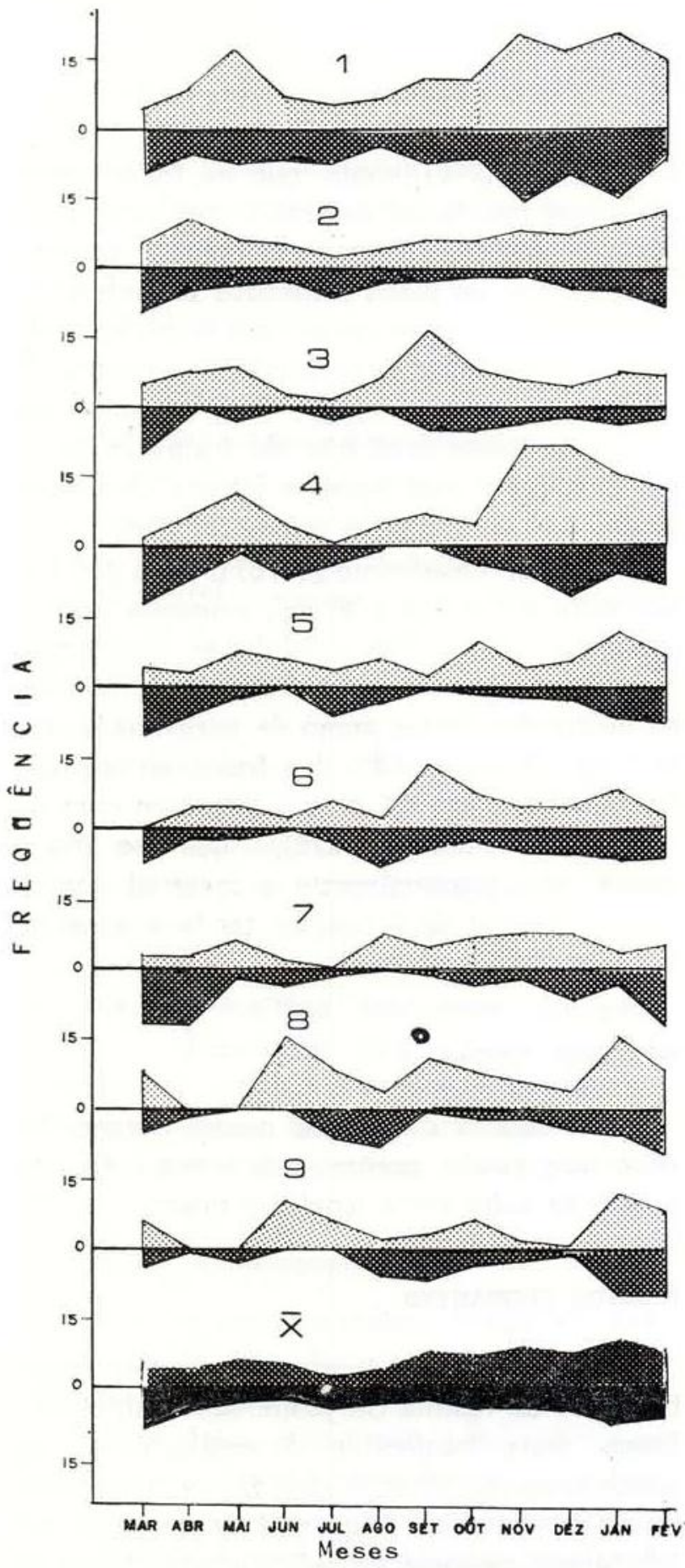

Fig. 1 - Dados fenológicos e de frutificação da gravioleira na região de Manaus (1978). Acima da abscissa, floraçâo; abaixo, frutificação. Os números acima de cada gráfico indicam a árvore. e flores da graviola, apresentando nítido comportamento de patrulhamento. Estas foram identificadas como Crematogaster sp (Myrmicinae-Crematogastrini) e Cephalotes atratus (L.) (Cephalotini) .

\section{ANÁLISE DE PRODUÇÃo}

A tabela 2 apresenta os dados básicos de produtividade com número de flores, frutos maduros e imaturos, peso dos frutos, sementes e safra e número de frutos perdidos.

Com exceção da correlação existente entre o número de flores e de frutos imaturos $\left(r=0,59^{*}\right)$, os outros parâmetros de produção, a diferença das espécies estudadas anteriormente, não apresentaram correlações significativas. Isto pode ter um significado importante no que se refere à cultura e tratamento dados à espécie.

Em primeiro lugar, uma frutificação de $40 \%$ (frutos imaturos) com relação ao número de flores não corresponde a nenhum dos dois modelos encontrados nas outras espécies desta série: grande número de flores e percentagem baixa de frutificação (umari, pajurá, sorva) ou número razoável de flores com altíssima percentagem de frutificação (mapati) (Falcão \& Lleras, 1980a, 1981a e b). O relatório da NAS (1975) anota que a polinização manual têm-se mostrado efetiva já que freqüentemente as anteras liberam o pólen antes que os estígmas estejam receptivos, o que leva à formação de frutos pequenos e disformes. $\mathrm{O}$ alto grau de frutos abortados (mais de $50 \%$ ) encontrados durante o desenvolvimento deste trabalho, apoia esta idéia de que existe algum problema básico no mecanismo de polinização da graviola.

Por outro lado, a falta de correlação entre os outros parâmetros de produção tais como frutos imaturos $x$ frutos maduros, flores $x$ peso da safra e frutos imaturos $x$ peso da safra sugerem que a espécie não está atingindo o investimento energético máximo na reprodução, e que o número de frutos maduros e peso da safra não estão sendo limitados através de controle fisiológico endógeno como foi postulado para as outras espécies estudadas nesta série. 
TABELA 2 - Annona muricata. Média dos dados básicos de produção, incluindo entre outros, flores, frutos imaturos e maduros e peso da safra das 10 árvores.

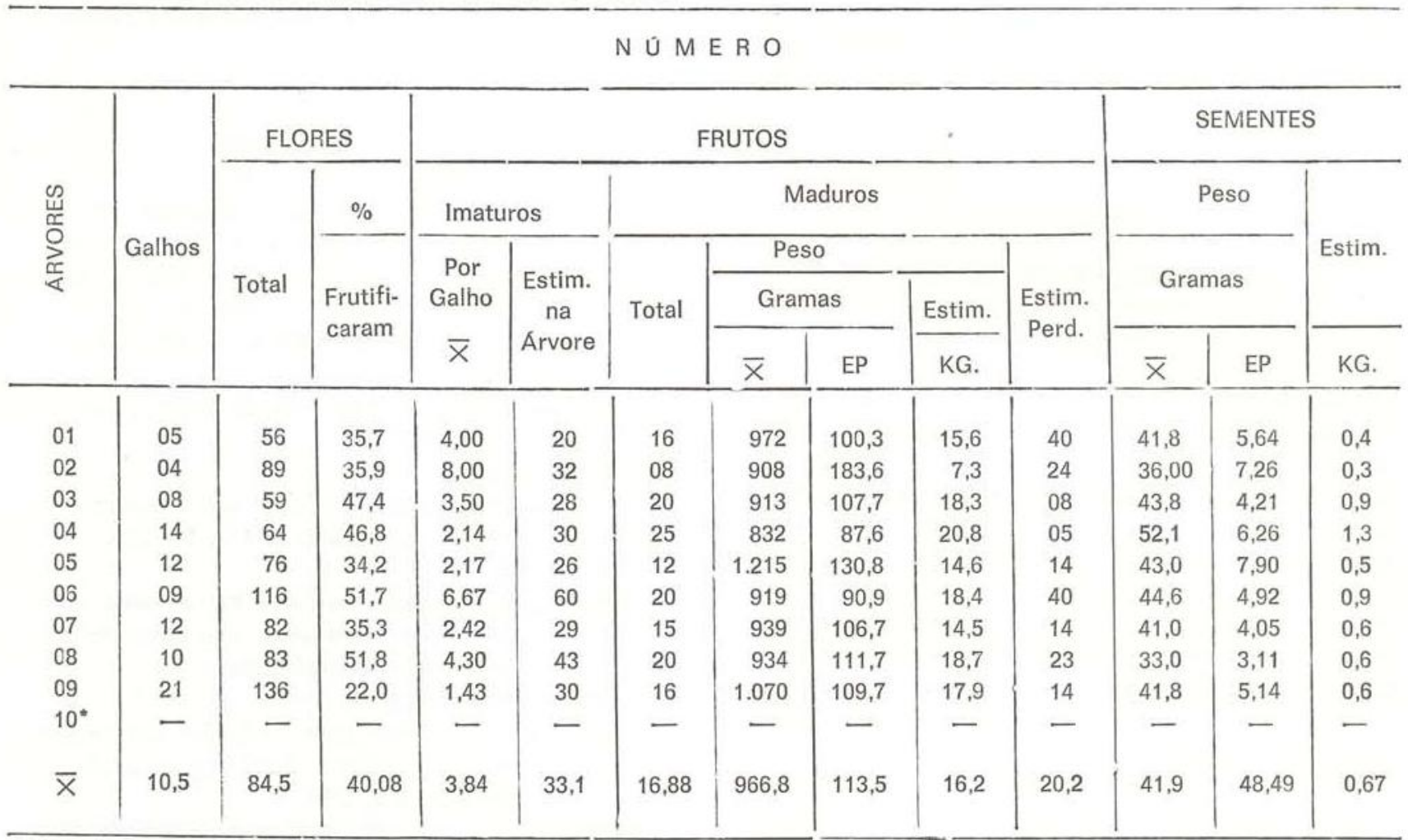

(") - A árvore 10 foi infestada por broca, morrendo durante o período de observaçăo.

Por um lado, isto é encorajador. já que sugere que com técnicas apropriadas, a produção da espécie pode ser aumentada significativamente sem maiores problemas. Por outro lado, surge um problema que pode ser mais difícil de resolver que o problema de aumentar a produção de uma espécie que anresenta polinização razoavelmente eficiente, e que consiste em modificar o sistema de reprodução de uma espécie que apresenta dissincronia freciüente entre a disponibilidade de pólen e a receptividade do estígma de maneira a fazer os mesmos sincrônicos.

Os resultados obtidos neste trabalho, quando comparados com produção da gravioleira em condições consideradas boas (Puerto Rico - NAS, 1975) não diferem consideravelmente, sendo que o material estudado nesta pesquisa não estava recebendo tratamento especial; uma produção estimada de 5 toneladas por hectare pode ser considerada aceitável. Porém, como anotado pela NAS (1975), comparada com outras espécies, é baixa.
Outro problema que terá que ser levado em conta na Amazônia, é a presença de broca que pode chegar a atacar $75 \%$ dos frutos, à semelhança do que ocorre no Suriname e Trinidade (NAS, 1975).

Uma série de problemas, quanto à cultura, tem sido levantada aqui, e que merece maiores pesquisas. Em primeiro lugar, deve iniciar-se (ou introduzir-se) a seleção de frutos de tamanho maior, já que os regionais são relativamente pequenos. Em segundo lugar, devem iniciar-se pesquisas em biologia reprodutiva para tentar obter-se sincrônia entre maturação do pólen a receptividede do estígma. Pesquisas entomológicas e de controle bioló. gico deverão ser realizadas para controlar as brocas, já que a única outra alternativa seria ensacar os frutos novos, o que pode ser impraticável.

\section{Agradecimentos}

Agradecemos ao Prof. Hugo Menezes dos Santos e sua equipe do Centro de Processamento de Dados, à Prof. ${ }^{a}$ Elizabeth Rodrigues 
de Oliveira Scafi, juntamente com os alunos finalistas de Estatística da Universidade do Amazonas. No trabalho de campo, somos gratos a Osmarino Santos Monteiro pela sua colaboração.

\section{SUMMARY}

Data on phenology, ecology and produtivity of the Soursop (Ännona muricata L.) are here presented for the vicinity of Manaus. Flowering and fruiting are continous throughout the year with a slight flowering peak between September and January and a a slight increase in fruiting (crop) between July and September. Even though a correlation is observed between number of flowers and fruit set, the same is not true between number of flowers and mature fruit (crop) which suggests that produtivity is not limited by endogenous control. With a mean production of $16 \mathrm{k}$ per tree, results are not significantly different from those observed in other regions; however, fruit size seems to be smaller than observed elsewhere.

Four species of Chrysomelid beattles were found visiting the flowers.

\section{REFERENCIAS BIBLIOGRÁFICAS}

\section{CAVALCANTE, P.B.}

1976 - Frutas comestiveis da Amazônia. 3 ed. Belém, INPA. 166p.

CLEMENT, C.R.; KERR, W.E.; WEBER, H.; FREITAS, E.; ARKCOLL, David E.; RANZANI, G. \& PAHLEN, E. van der.

1977 - Ecologia e Fruticultura da Amazônia. In: Seminários de Fruticultura, Manaus (mimeografado). 20p. (no prelo).

CORREA, P.

1926 - Dicionário das Plantas Úteis do Brasil e das Plantas Exóticas Cultivadas. Rio de Janeiro, Serviço de Inf. Agrícola. Vol. 5, 102p.

ERDTMIAN, G.

1960 - The acetolysis method: - a revised description. Sv. Bot. Tidskn. Lund, 54 (4): 561-664.
FALCÄO, M.A. \& LLERAS, E.

1980a- Aspectos Fenolćgicos, Ecológicos e de Produtividade do Umari (Poraqueiba sericea Tulasne). Acta Amazonica, 10 (3): 445-462.

1980b- Aspectos Fenológicos, Ecológicos e de Produtividade do Mapati (Pourouma cecropiifolia Mart.). Acta Amazonica, 10 (4): 711-724.

1981a- Aspectos Fenológicos, Ecológicos e de Produtividade do Pajurá (Couepia bracteosa Benth. . Acta Amazonica, 11 (3): 473-482.

1981b- Aspectos Fenológicos, Ecológicos e de Produtividade da Sorva (Couma utilis Muell, Arq.). Acta Amazonica, 11 (4): 729-741.

FONSECA, E.T.

1954 - Frutas do Brasil. Rio de Janeiro, Inst. Nac. Livro, 281p.

GOTTSBERGER, G.

1970 - Beiträge Zur Biologie von Annonaceen Blüten. Östen. Bot. Z. 118: 237-279.

LE COINTE, P.

1947 - A Amazônia Brasileira III. Árvores e plantas úteis (indígenas e aclimatadas) São Paulo, Ed. Nacional. 506p.

LEUNG, W.W.; FLORES, M.

1961 - Food Composition Table for use in Latim América National Institules of Health, Bethes de, Ma. USA.

MOURA, C.F.A.; de PECHNIK, E. \& de SIQUEIRA, R. 1951 - Valor nutritivo de frutos brasileiros. Arq. Bras. Nutrição, Tomo 8 n. 2, pág. 143-144.

NAS - National Academy of Sciences.

1975 - Underexploited Tropical Plants With Promising Economic Value. Washington Academy of Sciences, National, D.C.

PATIÑO, V.M.

1963 - Plantas cultivadas y Animales domésticos em América Equinoccial Tomo I: Frutales. Imprenta Departamental, Cali. Co'ombia. 547p.

PIJL, L. van der

1953 - On the flower biology of some plants from Java. Ann. Bogor. 1 (2).

PRANCE, G.T. \& SILVA, M.

1975 - Arvores de Manaus INPA, Manaus, 312p.

(Aceito para publicação em $08 / 01 / 82$ ) 